\title{
El liderazgo y su relación con la cultura organizacional en las pequeñas y medianas empresas familiares de Ciudad Obregón, Sonora
}

\section{Leadership and its relationship with the organizational culture in small and medium sized family businesses in Ciudad Obregon, Sonora}

\author{
María Olivia Palafox-Soto ${ }^{1}$ (iD https://orcid.org/0000-0002-8245-3032 \\ Sergio Ochoa-Jiménez ${ }^{1}$ (D) http://orcid.org/0000-0003-1848-3760 \\ Carlos Armando Jacobo-Hernández ${ }^{1}$ (D) https://orcid.org/0000-0002-8524-6258 \\ ${ }^{1}$ Instituto Tecnológico de Sonora, ${ }^{\square}$ sergio.ochoa@itson.edu.mx
}

Recibido en: 10 - 09 - 2020 / Aceptado en: 12 - 12 - 2020

\section{Resumen}

Introducción: Las empresas familiares son consideradas de gran importancia gracias al potencial que ofrecen en aspectos de rentabilidad y productividad a nivel mundial, sin embargo, presentan problemas en su gestión, cultura y liderazgo; por ello el objetivo del presente trabajo analizar los estilos de liderazgo (autocrático, democrático, de consulta y participativo) en relación con los tipos de cultura (clan, adhocrática, mercado y jerárquica), con el fin de identificar cómo se relacionan estos dos aspectos y lograr que las empresas familiares continúen aportando a la economía, siendo rentables, favoreciendo su permanencia y demostrando lo fundamental que son.

Método: Se realizó un estudio cuantitativo, transversal, a través de un cuestionario con 26 preguntas enfocadas a la cultura organizacional basado en Cameron y Quinn, así como diversos estilos de liderazgo expuestos por Hofstede; mismo que se aplicó a 156 informantes, cuyo análisis de información fue llevada a cabo por medio de un análisis de regresión logística multinomial en el programa SPSS versión 25.

Resultados: Se encontró que en las empresas familiares es más probable que exista cualquier otro tipo de liderazgo sobre el autocrático. Asimismo, al relacionar el tipo de cultura con el liderazgo, se evidencia que en una cultura tipo clan es más probable que se ejerza un liderazgo democrático que uno autocrático, además, cuando prevalece una cultura tipo mercado es más probable que exista un liderazgo participativo que uno autocrático, en contraparte, en una empresa con cultura jerárquica, es más probable que exista un liderazgo autocrático que cualquiera de los otros.

Discusión o Conclusión: Tanto el liderazgo como la cultura organizacional se relacionan entre sí, y son prueba de que las empresas sean de carácter familiar o no, pueden seguir subsistiendo con un futuro prometedor si buscan centrar sus esfuerzos en mejorar la relación entre estos dos aspectos; 
además, cabe resaltar que esta es una de las escazas investigaciones realizadas en empresas de carácter familiar con el método utilizado en la presente.

Palabras clave: liderazgo; organizaciones; empresa familiar; cultura organizacional; negocios

\begin{abstract}
Introduction: Family businesses are considered of great importance thanks to the potential they offer in aspects of profitability and productivity at a global level; however, they present problems in their management, culture, leadership, among others. It is fundamental to analyze the leadership styles (autocratic, democratic, consultative, and participatory) in relation to the types of culture (clan, adhocratic, market, and hierarchical) in order to identify how these are related, and to ensure that family businesses continue to contribute to the economy, being profitable, favoring their permanence and demonstrating how fundamental they are.

Method: A quantitative, transversal study was carried out through a questionnaire with 26 questions focused on the organizational culture based on Cameron and Quinn, as well as diverse leadership styles exposed by Hofstede; this was applied to 156 informants, whose information analysis was carried out through a multinomial logistic regression analysis in software SPSS version 25 .
\end{abstract}

Results: It was found that in family businesses any other type of leadership over the autocratic is more likely to exist; likewise, when relating the type of culture with leadership, it is evident that in a clan-type culture it is more likely that democratic leadership is exercised than autocratic leadership. When a market-type culture prevails, it is more likely that participatory leadership exists than autocratic leadership; in contrast, in a company with a hierarchical culture, autocratic leadership is more likely than any of the others.

Discussion or Conclusion: Both leadership and organizational culture are related to each other, and are proof that companies, whether they are family-owned or not, can continue to subsist with a promising future if they seek to focus their efforts on improving the relationship between these two aspects; furthermore, it should be noted that this is one of the few research carried out in family-owned companies with the utilized method in the present one.

Keywords: leadership; organizations; family business; organizational culture; business 


\section{Introducción}

Las empresas familiares son organizaciones unidas por lazos sanguíneos donde la propiedad pertenece a los miembros de la propia familia, son consideradas importantes por ser capaces y competentes para permanecer dentro del mercado a través del tiempo (Molina, Botero \& Montoya, 2007), se caracterizan por ser productivas en diversos aspectos, tales como económicos, sociales, entre otros (Soto, 2011), además, ayudan a la economía a nivel mundial y pertenecen a diversas regiones y actividades (González \& Olivié, 2018).

Se destacan por ser empresas de éxito debido a su importancia económica y a la capacidad para generar empleos considerándose $19 \%$ mejores que las que no lo son en términos de rentabilidad (Libre Mercado, 2018), además, existen empresas familiares que han crecido y son reconocidas a nivel mundial destacándose por tener mayores ingresos (Forbes, 2018). En México, las empresas familiares generan aspectos positivos como prosperidad, seguridad, innovación, bienestar económico (Rodríguez-Suárez, Pico-González, \& Méndez-Ramírez, 2013), mejor comunicación, fomento de valores, buena toma de decisiones, entre otros (Aira, 2016).

Una empresa familiar puede tener diferentes conceptualizaciones dependiendo en gran medida de cada investigador, Chua, Chrisman y Sharman (1999) mencionan que no existe una norma o alguna regla que permita asegurar la validez de una conceptualización única para lo que significa una empresa familiar, por lo cual, basados en Tagiuri y Davis (1996) se define a las empresas de carácter familiar como aquellas donde tienen al menos dos características: propiedad

y dirección estructuralmente hablando, es decir que los dueños sean familiares aunque no laboren en la misma, pero si un familiar consanguíneo de ellos.

Crear una empresa es complejo, pero crear y mantener una empresa familiar lo es aún más, ya que desde que surge hasta su consolidación, emergen problemáticas y adversidades que se tornan más complicadas con el paso del tiempo (Meza, 2017) por eso, en muchas ocasiones el continuar de pie con una organización de carácter familiar aminora hasta el punto de desaparecer, pues es una de sus mayores dificultades (Quejada \& Ávila, 2016), y es que alrededor del mundo, las oportunidades de sobrevivir de generación en generación en este tipo de empresas, son bajas (Gómez, 2015).

González y Olivié (2018) afirman que del total de empresas familiares que son creadas, más del 50\% de ellas no logra traspasar la propiedad a la segunda generación; pues sus dificultades sobrepasan sus habilidades para llevar a cabo una buena gestión lo que les impiden seguir 
subsistiendo (Burgoa, Herrera, \& Treviño, 2013), además de tener problemas entre el negocio y la familia por no ejercer un liderazgo para tener una eficiente gestión, por esa razón su ejercicio se ha considerado relevante dentro de este tipo de organizaciones (Red de cátedra de la empresa familia, 2018).

Así pues, el liderazgo se ha convertido en un factor clave dentro de las organizaciones ya que permite tener a personas capaces que sepan adaptarse, tomar decisiones, resolver problemas y salir adelante con eficacia (Gómez-Rada, 2011), asimismo, dicho aspecto hace que las cosas funcionen dejando al frente a personas que tienen la labor de ser sabias al hacer cualquier actividad (Witzel, 2012), también es una herramienta clave para inspirar y motivar a los empleados; pues requiere de esfuerzo, es fiable y favorable para resolver aspectos que se desprenden en las empresas familiares como problemas económicos, procesos de sucesión, gobernanza, entre otros (Burkart, Panunzi, Shleifer, 2003), por lo cual, a través de los años el ejercer liderazgo en la gestión de las organizaciones se ha vuelto cada vez más relevante pues permite lograr el mejoramiento de actitudes, superación de riesgos y obstáculos, mejor visión, entre otros aspectos (Kouzes \& Posner, 2002).

El tiempo, la experiencia y las investigaciones realizadas demuestran que el liderazgo es prueba de competitividad, calidad, permanencia y éxito, por ello es necesario impulsar la cultura organizacional para lograr grandes cambios (Aguirre, Serrano y Sotomayor, 2017); es así que hoy en día nadie puede negar que el ejercicio del mismo puede poner en peligro una empresa, pues repercute directamente en su rendimiento (Salazar, 2006).

Dentro de las empresas familiares, la cultura organizacional puede ser una de sus características distintivas, por el hecho de que se trabaja con la familia dentro de ella y la manera de relacionarse (Bastar, 2006), es por ello que de no prestar atención a este aspecto puede agravar cualquier situación dentro de la organización, repercutiendo en los resultados y ocasionando aspectos desfavorables en ella (Toca \& Carrillo, 2009), por tal razón, la cultura organizacional es también un factor determinante para su sobrevivencia (Roldan \& Bray, 2012).

De igual forma, analizar la cultura organizacional se ha considerado como un elemento sustancial en las empresas de todo tipo y de cualquier sector, y relacionándola a las empresas de carácter familiar resulta ser fundamental ya que permite comprender la conducta de los trabajadores en este tipo de empresas (Cruz \& Torres, 2014). 
De acuerdo con García (2006) la cultura organizacional engloba elementos importantes como aspectos simbólicos y de reconocimiento dentro de las mismas; permitiendo que las empresas alcanzan la calidad total, prácticas de supervisión y comportamientos sociales, como la práctica de los valores, costumbres, actitudes, aprendizajes, historia, tradiciones, entre otros (González \& Fernández, 2000) además de lograr un buen cambio hacia una mejor productividad (Pérez, 2009).

Es por ello, que Siliceo, Casares y González (1999) mencionan que los responsables de las organizaciones considerados como los líderes son quienes deben fomentar una cultura organizacional sana y proactiva dentro de las mismas, logrando la productividad, lealtad y confianza en sus trabajadores para el beneficio de la empresa, buscando ser grandes visionarios, inspiradores y motivadores; también, deben propiciar el buen cambio en la cultura de la organización, ya que son ellos quienes la construyen (Pirela, 2010).

Así pues, Boada, Vallejo y Macip (2001) establecen que la cultura organizacional es un aspecto subyacente de las organizaciones, es decir que se encuentra en su interior y no puede ser observado a simple vista, sin embargo, quienes están dentro de la misma son capaces de percibirla al igual que el liderazgo, si estos aspectos se ven afectados, la organización completa también, llevándola al fracaso.

Por lo cual, las investigaciones realizadas sobre ambas variables establecen que tanto la cultura organizacional como el liderazgo pueden comportarse de manera diferente dependiendo del contexto en el que se encuentren y la forma en que se analicen, desconociendo si el liderazgo se ve influenciado por la cultura organizativa o si la cultura se ve influenciada por el liderazgo y ello es comprobado en diversas investigaciones (León, 2001).

Es por ello que la importancia de comprender la relevante aportación que trae consigo el presente estudio, pues estudiar la cultura organizacional se ha vuelto fundamental en las empresas y analizar los estilos de liderazgo se ha considerado de gran importancia, ya que permite ir más allá tendiendo una gran visión y haciendo grandes cambios dentro de la organización (Stone-Johnson, 2014).

De igual forma, la importancia del liderazgo como de la cultura organizacional dentro de la gestión empresarial permite lograr que todos los integrantes sean comprometidos tanto con el cambio y las decisiones a tomar, ya que para realizar cualquier proceso estratégico en las empresas es necesario contar con el ejercicio de liderazgo y el fomento de una buena cultura organizacional (Lapo \& Jácome, 2015). 
Por otro lado, se han encontrado diversos estudios donde relacionan la cultura con el liderazgo, el impacto que tienen una sobre la otra y si estos componentes permiten el éxito (Schimmoeller 2010; Tsui, Zhang, Wang, Xin \& Wu 2006) o comprenden la dinámica dentro de la gestión (Coury \& Peçanha 2016), así como la relación con un solo estilo de liderazgo, y con aspectos como el clima organizacional ya que su influencia repercute en el buen funcionamiento de las organizaciones (Lescano, 2017); también estudios donde se analizan los perfiles de liderazgo de diferentes lugares y conocer si hay diferencias culturales (Espinoza, Contreras \& Barbosa, 201), así como el comportamiento de los líderes (Taormina 2008).

Además, existen otras investigaciones donde especifican las percepciones de estilos de liderazgo transformacional y transaccional en relación con la cultura organizacional (Pirela, 2010); o solamente el liderazgo transformacional (Frontiera 2010; Soumendu 2009) así como relacionar estos dos estilos con el liderazgo ético y la cultura (Shamas-ur-Rehman \& Ofori 2009), de igual forma el estudiar el promover el liderazgo en mujeres dentro de la cultura organizacional (Howard, 2006); el análisis del liderazgo de genero (Alabart, (Cruz \& Pila 2006), liderazgo carismático (Wilderon, Van den Berg, \& Wiersma, 2012), el liderazgo autentico que promueve satisfacción laboral (Azanza, Moriano \& Molero 2013), así como estudios de aspectos teóricos sobre estos fenómenos de estudio (León, 2001; Rivera, 2016; Vázquez, 2013).

Cabe mencionar que, se encontró en un estudio que el estilo de liderazgo denominado transformacional tiene una correlación positiva con el tipo de cultura clan y adhocrática pero no con la cultura de mercado y jerárquica, resaltando que el liderazgo transformacional mantiene mayores niveles de correlación que el estilo transaccional, por otra parte, el estilo de liderazgo laissez faire tiene una correlación positiva con la cultura jerárquica pero no con las culturas clan, adhocrática y mercado (Schimmoeller, 2010).

De igual forma, otra investigación analizada establece que, dados los niveles de significancia obtenidos, el liderazgo democrático y de consulta tienen una relación positiva y significativa con la cultura clan, y el liderazgo participativo con la cultura adhocrática (Giritli, Öney-Yaz, Topçu-Oraz, \& Acar, 2013).

Aunado a lo anterior, con base en los autores antes mencionados es importante tener en cuenta que las investigaciones relacionadas con el liderazgo y cultura organizacional abarcan diversos contextos como en instituciones bancarias, firmas de abogados, instituciones educativas, 
parroquias, hospitales entre otros, donde han sido analizadas, no obstante, aún quedan más contextos los cuales se debieran estudiar, como en las empresas familiares.

Asimismo, la mayoría de las investigaciones solo se encuentran enfocadas en establecer sus análisis con un solo estilo de liderazgo cuando existen más de ellos y que son analizados en las investigaciones, entre lo más comunes son los que mencionan Blake y Mouton (1980) pues afirman que, a partir de ellos, existen muchos más, los cuales son considerados los más frecuentes y analizados en diversas investigaciones.

Por lo cual, para la presente investigación surge la necesidad de analizar la relación que existe entre el liderazgo de los responsables de la empresa y los tipos de cultura organizacional, centrándolo en las empresas de carácter familiar, específicamente el liderazgo autocrático, democrático, de consulta y participativo en relación con el tipo de cultura clan, adhocrática, mercado y jerárquica.

Así pues, dicha investigación, permitirá tener un conocimiento más amplio sobre los estilos de liderazgo más utilizados en las empresas hoy en día, así como los tipos de cultura que caracterizan a las organizaciones, además de conocer la relación que existe entre ambas variables y de esta forma ayudar a las empresas familiares a optar por siempre tomar buenas decisiones que ayuden a dirigir el rumbo de la organización.

Además, este tipo de investigaciones permitirá tener un conocimiento para las demás organizaciones, ayudándolas a lograr que exista una mejor toma de decisiones dentro de su gestión, al mismo tiempo de poder conocer que gracias al liderazgo y a un buen clima y cultura organizacional dentro de la misma permitirá tener eficacia dentro de la empresa (Mendoza \& Ortiz, 2006) y eficiencia gracias a su influencia (Quintanilla \& Moreira, 2016) lo que centrándolo a una empresa familiar traerá relaciones entre la propia familia, evitando los malos entendidos y problemas.

\section{Método}

La presente investigación fue tipo cuantitativa, no experimental, con un diseño transeccional, efectuándose por medio de un censo, es decir a todos los elementos que conformaron el total de la población (Torres, Paz \& Salazar, 2002), las cuales fueron pequeñas y medianas empresas del sector comercial ubicadas en Ciudad Obregón, Sonora México y obtenidas del Directorio Estadístico Nacional de Unidades Económicas (DENUE). 
Cabe mencionar que se eligió a este sector por la relevancia que mantiene a diferencia de otros, ya que el objetivo de estas empresas es que pueden tener acceso a cualquier determinado producto sin que exista de por medio la distancia para conseguirlo, con solo un poco de inversión inicial es suficiente para emprender y crecer en el futuro, también es considerado el más preferido por generar resultados más rápidos y porque brinda viabilidad y estabilidad a diferencia de otros; además alcanzando procesos de globalización es posible lograr un mejor desarrollo económico a nivel global (Pico \& López, 2006). Es por ello que, las empresas que van surgiendo en Ciudad Obregón se están uniendo cada vez más a este sector, además, gran parte de las que ya existen son comerciales. por lo que su relevancia es inminente.

Por otra parte, más del $50 \%$ del total de empresas son pertenecientes al sector comercial, en donde 42,677 son del estado de Sonora, además, el comercio es de las principales actividades que más se desarrollan en el estado en un $10.3 \%$ por debajo de fabricación de maquinaria y equipo y minería no petrolera, ocupando también el 12vo lugar a nivel nacional en economías que facilitan la creación de negocios (CONCANACO, 2018). Asimismo, de acuerdo con la Secretaría de Hacienda (2019) en el año 2018 el PIB representó más del 18\% en el sector comercio dentro del estado de Sonora.

Debido al desconocimiento que se tiene en la definición de las empresas familiares por no existir una base de datos que especifique cuales son catalogadas como tal, se encuestaron a todas las empresas que quisieron colaborar con la investigación, de 380 organizaciones, se obtuvo información de 130, descartando algunas por estar duplicadas, ser sucursales, estar clausuradas o por no aceptar responder.

De las 130 empresas obtenidas se obtuvieron 156 instrumentos encuestando a los responsables o personas en puestos medios y bajos con la finalidad de analizar la variabilidad en la tendencia de respuesta por parte de trabajadores con puestos distintos de acuerdo a su perspectiva, es por ello que se pidió la participación de más informantes en algunas organizaciones de las que se pudo acceder con mayor facilidad.

Una vez encontrado el instrumento con ambas variables se realizó una operacionalización y adaptación del mismo, tomando como referente uno establecido en la investigación de Giritli, Öney-Yaz, Topçu-Oraz y Acar (2012), el cual se basa en autores básicos de cada una de las variables, utilizando para la parte de cultura organizacional el Organizational Culture Assessment Instrument (OCAI) de Cameron y Quinn (1999) compuesto por cuatro dimensiones que son 1) 
clan, 2) adhocrática, 3) mercado y 4) jerárquica que a su vez están compuestas por seis subdimensiones, las cuales son: 1) características dominantes, 2) liderazgo organizacional, 3) gestión de empleados, 4) cohesión organizacional, 5) énfasis estratégico y 6) criterios de éxito, formando un total de 24 preguntas, a través de una escala tipo Likert, compuesta de 5 niveles que va desde Totalmente en desacuerdo, En desacuerdo, Ni de acuerdo ni en desacuerdo, De acuerdo hasta Totalmente de acuerdo; y para la parte de liderazgo el cuestionario de valores VSM 94 de Hofstede (1998), estableciendo dos preguntas para conocer la forma en que trabaja el líder y como les gustaría que trabajara según los integrantes de la empresa cuyas opciones de respuesta dadas fueron cuatro estilos de liderazgo que son: el estilo autocrático, democrático, de consulta y participativo (Ver Apéndice 1).

Cabe mencionar que se eligió el instrumento de evaluación de la cultura organizacional, no solo por lo que los autores que lo crearon establecen que una empresa pueden converger distintos tipos de cultura sino también porque permite analizar a la empresa desde una percepción colectiva que diagnostica aspectos importantes de la misma como lo que es en general una organización, el enfoque que está impregnado, los diversos mecanismos de unión, estrategia y la manera en que se define el éxito de la empresa; (Cameron y Quinn, 1999) además de ser un instrumento replicado en muchos estudios alrededor del mundo

Por otro lado, el instrumento de la encuesta de valores de Hofstede (VSM), fue seleccionado debido a que ayuda a analizar el patrón y la frecuencia percibida del comportamiento del liderazgo observado (Hofstede, 1998), es decir cómo se toman las decisiones dentro de la gestión de la empresa y como éstas son observadas y percibidas por los demás integrantes de la organización, adaptándolas de manera en que los integrantes de la organización puedan identificar fácilmente el liderazgo ejercido dentro de la empresa.

Se aplicó una prueba piloto a un total de 30 empresas. Una vez terminada la aplicación de la prueba piloto mostrando que tiene confiabilidad, al obtener un alfa de Cronbach por arriba el 0.90, al conseguir que las dimensiones se agruparan correctamente en el análisis factorial y que los datos fueran normales, solamente se hicieron algunos cambios como reacomodo de preguntas y se agregaron opciones en las preguntas generales, para proceder con la aplicación de todos los demás instrumentos a la población seleccionada.

A continuación, se procesó la información obtenida analizando e interpretando los datos para conseguir los resultados por medio de un análisis de regresión logística multinomial, pues de 
acuerdo con Hosmer y Lemeshow (2000) este análisis es usado para problemas multiclase y cuando la variable dependiente es categórica de tipo nominal, es decir con más de dos categorías u opciones de respuesta, por lo cual fue usado para la presente investigación, el objetivo de este método es modelar las elecciones de respuesta, pudiendo predecir las probabilidades de que suceda algo o de los diferentes resultados posibles

El análisis de regresión logística multinomial conocido como RLM por sus siglas en ingles ayuda a predecir la variable dependiente politómica que está dada por diversas variables independientes, ya que este método establece que la probabilidad de elección en las respuestas no dependen ni cambian de otras probabilidades independientemente si se agregan o desaparecen otras más (Valencia \& Bonifaz, 2018), permite obtener explicaciones más detalladas y explicables en cuanto a las distintas posibilidades de comparación entre las variables analizadas (Shanock, Baran, Gentry, Pattison \& Heggestad, 2010).

Cabe mencionar, que la RLM no muestra pruebas de normalidad de datos, linealidad ni suposición de los mismos para las variables consideradas independientes (estilos de liderazgo), las cuales están dadas o dentro de la variable dependiente (liderazgo), considerándose por ello una técnica paramétrica (Giritli, Öney-Yaz, Topçu-Oraz, \& Acar, 2013); no obstante, existen otras formas que permiten conocer si los análisis de este método son eficaces ayudando y aportando una mayor explicación y comparabilidad entre las variables de estudio, como las pruebas de verosimilitud y bondad del ajuste que aportan a dar una mayor explicación entre las variables de estudio.

\section{$\underline{\text { Resultados }}$}

Se muestra un integrado de los datos demográficos de la población seleccionada (ver Tabla 1) donde se especifica a detalle la información recopilada en las empresas visitadas. 
Tabla 1. Integrado de datos demográficos.

Table 1. Demographic data.

\begin{tabular}{|c|c|}
\hline $\begin{array}{l}\text { Preguntas generales } \\
\text { General Questions }\end{array}$ & $\begin{array}{l}\text { Datos demográficos } \\
\text { Demographic data }\end{array}$ \\
\hline Antigüedad de la empresa & $\begin{array}{l}\text { De } 1 \text { a } 5 \text { años }=10 \% ; \text { De } 6 \text { a } 10 \text { años }=12 \% \text {; De } 11 \text { a } 15 \text { años=12\%; De } 16 \text { a } 20 \\
\text { años }=16 \% ; 21 \text { o más }=50 \%\end{array}$ \\
\hline Tamaño de la empresa & Micro $=22 \% ;$ Pequeña $=56 \% ;$ Mediana $=14 \%$ Grande $=8 \%$ \\
\hline Familiares del dueño & $0=40 \% ; 1=10 \% ; 2=20 \% ; 3=7 \% ; 4=23 \%$ \\
\hline Puesto del trabajador & Dueño $=1 \%$; Gerente $=50 \%$; Subgerentes $=7 \%$; Empleados $=60 \%$ \\
\hline Sexo & Masculino $=55 \% ;$ Femenino $=45 \%$ \\
\hline Estado Civil & Casado $=64 \% ;$ Soltero $=36 \%$ \\
\hline Edad & Menos de $20=2 \% ; 21-30=36 \% ; 31-40=35 \% ; 41-50=21 \% ; 51$ o más $=6 \%$ \\
\hline Antigüedad & $\begin{array}{l}\text { De } 1 \text { a } 5 \text { años }=65 \% ; \text { De } 6 \text { a } 10 \text { años }=13 \% ; \text { De } 11 \text { a } 15 \text { años }=11 \% ; \text { De } 16 \text { a } 20 \\
\text { años }=6 \% ; 21 \text { o más }=5 \%\end{array}$ \\
\hline Escolaridad & Secundaria $=13 \%$; Preparatoria $=33 \%$; Licenciatura $=49 \%$; Otro $=5 \%$ \\
\hline
\end{tabular}

Fuente: Elaboración propia.

Source: Own elaboration.

Se muestra el análisis de confiabilidad para cada uno de los cuatro tipos de cultura donde el nivel sobrepasó el 0.80, lo que indica que los análisis son confiables (ver Tabla 2).

Tabla 2. Estadísticos descriptivos.

Tabla 2. Descriptive statistics.

\begin{tabular}{|ccccc|}
$\begin{array}{c}\text { Tipos de cultura } \\
\text { Culture types }\end{array}$ & $\mathbf{N}$ & Media & $\begin{array}{c}\text { Alfa de } \\
\text { Desviación estándar } \\
\text { Estándar deviation }\end{array}$ & $\begin{array}{c}\text { Cronbach } \\
\text { Cronbach's } \\
\text { alpha }\end{array}$ \\
\hline Clan & 156 & 4.01 & .73 & 0.874 \\
Adhocrática & 156 & 3.86 & .67 & 0.839 \\
Mercado & 156 & 3.98 & .67 & 0.853 \\
Jerárquica & 156 & 3.97 & .70 & 0.887 \\
\hline
\end{tabular}

Fuente: Elaboración propia.

Source: Own elaboration.

De igual forma, también se muestra cada una de las definiciones de los cuatro estilos de liderazgo analizados en la investigación (ver Tabla 3). 
Tabla 3. Descripción de los estilos de liderazgo.

Table 3. Styles leadership description.

\begin{tabular}{|ll|}
\hline $\begin{array}{c}\text { Estilos de liderazgo } \\
\text { Leadership styles }\end{array}$ & \multicolumn{1}{c|}{$\begin{array}{c}\text { Definición } \\
\text { Definition }\end{array}$} \\
\hline Autocrático & $\begin{array}{l}\text { Este estilo de liderazgo se caracteriza por dar órdenes, esperando que sean acatadas } \\
\text { y llevadas a cabo en todo momento por todos los subordinados. }\end{array}$ \\
Democrático & $\begin{array}{l}\text { A este tipo de liderazgo también se le conoce como paternalista o persuasivo, } \\
\text { conocido por tomar en cuenta a los demás, y caracterizado porque antes de tomar } \\
\text { alguna decisión trata de explicar todo a los subordinados. }\end{array}$ \\
De consulta & $\begin{array}{l}\text { Es conocido por tomar en cuenta lo que piensan los demás, escuchando lo que tienen } \\
\text { que decir al momento de tomar cualquier decisión, aquí los empleados tienen } \\
\text { derecho a opinar antes de llegar a una decisión definitiva. }\end{array}$ \\
Participativo & $\begin{array}{l}\text { Se caracteriza por hacer una toma de decisiones en conjunto, es decir convocar a } \\
\text { todos los subordinados de cualquier nivel a una reunión y entre todos tomar la mejor } \\
\text { decisión, debatiendo cualquier problema y aceptando como decisión definitiva la } \\
\text { opinión de la mayoría para seguir adelante. }\end{array}$ \\
\hline
\end{tabular}

Fuente: Elaboración propia con base en Giritli, Öney-Yaz, Topçu-Oraz y Acar (2013).

Source: Own elaboration base on Giritli, Öney-Yaz, Topçu-Oraz y Acar (2013).

Dentro de la gestión de las organizaciones se tiende a tener un tipo de liderazgo autocrático, lo que significa que están más expuestos a solo recibir órdenes de parte de sus superiores sin tener opinión al respecto de lo que se tenga que hacer, siguiendo con un estilo democrático donde ya se tiende a poder tomar en cuenta a todos los trabajadores al momento de tomar una decisión, no obstante, no significa que le tomen demasiada importancia a lo que todos los empleados piensan sobre la gestión de la organización (ver Tabla 4).

Tabla 4. Estadísticos descriptivos de los estilos de liderazgos actuales.

Table 4. Descriptive statistics of actual leadership styles.

\begin{tabular}{|ccccc|}
$\begin{array}{c}\text { Estilos de } \\
\text { liderazgo } \\
\text { Leadership styles }\end{array}$ & Frecuencia & $\begin{array}{c}\text { Porcentaje } \\
\text { valido } \\
\text { Valid }\end{array}$ & $\begin{array}{c}\text { Porcentaje valido } \\
\text { Valid percentage }\end{array}$ & $\begin{array}{c}\text { Porcentaje } \\
\text { acumulado } \\
\text { Accumulated } \\
\text { percentage }\end{array}$ \\
\hline Autocrático & 68 & 43.6 & 43.6 & 43.6 \\
Democrático & 38 & 24.4 & 24.4 & 67.9 \\
De consulta & 33 & 21.2 & 21.2 & 89.1 \\
Participativo & 17 & 10.9 & 10.9 & 100.0 \\
Total & 156 & 100.0 & 100.0 & \\
\hline
\end{tabular}

Fuente: Elaboración propia.

Source: Own elaboration

Asimismo, se presenta la eficacia del método de regresión mutinomial utilizado, por medio de pruebas de verosimilitud a través del coeficiente de chi cuadrado, donde el nivel de significancia 
se encuentra por debajo de 0.05 , lo que significa que las variables independientes (liderazgo) aportan a explicar la variable dependiente (tipos de cultura) en la investigación, apoyando así a la existencia de una relación (ver Tabla 5).

Tabla 5. Información del ajuste del modelo.

Tabla 5. Model adjust Information.

\begin{tabular}{|c|c|c|c|c|}
\hline \multirow[t]{2}{*}{$\begin{array}{l}\text { Modelo } \\
\text { Model }\end{array}$} & \multirow{2}{*}{$\begin{array}{c}\text { Criterios de ajuste } \\
\text { de modelo de } \\
\text { logaritmo de la } \\
\text { verosimilitud }-2 \\
\text { Model fit criteria } \\
\text { likelihood logarithm } \\
-2\end{array}$} & \multicolumn{3}{|c|}{$\begin{array}{c}\text { Pruebas de la razón de verosimilitud } \\
\text { Likelihood ratio tests }\end{array}$} \\
\hline & & $\begin{array}{l}\text { Chi-cuadrado } \\
\text { Chi-squared }\end{array}$ & $\begin{array}{l}\text { Gl } \\
\text { gl }\end{array}$ & $\begin{array}{l}\text { Sig. } \\
\text { Sig. }\end{array}$ \\
\hline Sólo intersección & 396.760 & & & \\
\hline Final & 353.891 & 42.870 & 24 & .010 \\
\hline
\end{tabular}

Fuente: Elaboración propia.

Source: Own elaboration

De las variables independientes predictoras se eligió la variable de referencia en el modelo de regresión logística multinomial (Gómez \& Palacios, 2013), en este caso, fue el liderazgo autocrático por ser la variable con la que se podía hacer más comparaciones dentro del modelo; por otro lado, en las variables de control se seleccionaron el tipo y los tamaños de la organización.

Dado los resultados arrojados en el modelo de regresión logística multinomial que pueden observarse en la tabla cabe resaltar que en las empresas familiares del sector comercial de Ciudad Obregón, Sonora es más probable que exista cualquier tipo de liderazgo que uno autocrático, por otro lado, cuando una empresa está enfocada hacia una cultura clan es más probable que exista un liderazgo democrático que uno autocrático, además, cuando una cultura jerárquica prevalece en una organización, es más probable que predomine un estilo de liderazgo autocrático que un liderazgo democrático (ver Tabla 6).

Cabe mencionar, que cuando en una organización se crea una cultura de compromiso y mayor participación (clan), es importante que se preocupen los empleados informándoles sobre las decisiones a tomar (democrático). Por otro lado, cuando en una organización están enfocados por la eficiencia, la estabilidad y control de las actividades (jerárquica), es sustancial que exista quien imponga las reglas y ordene lo que se debe de hacer en cualquier circunstancia (autocrático). 
Tabla 6. Estimaciones de parámetros.

Table 6. Parameter estimates.

\begin{tabular}{|c|c|c|c|c|c|c|c|c|c|}
\hline \multirow{2}{*}{$\begin{array}{l}\text { Liderazgo Actual* } \\
\text { Actual leadership* }\end{array}$} & & B & $\begin{array}{l}\text { Desv. } \\
\text { Error }\end{array}$ & Wald & gl & \multirow{2}{*}{$\begin{array}{l}\text { Sig. } \\
\text { Sig }\end{array}$} & \multirow{2}{*}{$\begin{array}{l}\operatorname{Exp}(B) \\
\operatorname{Exp}(B)\end{array}$} & \multicolumn{2}{|c|}{$\begin{array}{l}95 \% \text { de intervalo de } \\
\text { confianza para } \operatorname{Exp}(B) \\
95 \% \text { confidence Interval } \\
\text { for } \operatorname{Exp}(B)\end{array}$} \\
\hline & & B & $\begin{array}{l}\text { Estándar } \\
\text { deviation }\end{array}$ & Wald & gl & & & $\begin{array}{l}\text { Límite } \\
\text { inferior } \\
\text { Lower } \\
\text { limit }\end{array}$ & $\begin{array}{l}\text { Límite } \\
\text { superior } \\
\text { Upper limit }\end{array}$ \\
\hline \multirow{5}{*}{ Democrático } & Intersección & -2.442 & 1.697 & 2.071 & 1 & .150 & & \multirow{5}{*}{$\begin{array}{l}1.250 \\
.068 \\
1.675\end{array}$} & \multirow{5}{*}{$\begin{array}{l}10.304 \\
.690 \\
10.914\end{array}$} \\
\hline & Clan & 1.278 & .538 & 5.636 & 1 & .018 & 3.588 & & \\
\hline & Jerárquica & -1.530 & .591 & 6.699 & 1 & .010 & .217 & & \\
\hline & Familiar & 1.453 & .478 & 9.231 & 1 & .002 & 4.275 & & \\
\hline & Intersección & -4.467 & 1.994 & 5.021 & 1 & .025 & & & \\
\hline \multirow{3}{*}{ De consulta } & Jerárquica & -1.323 & .597 & 4.903 & 1 & .027 & .266 & \multirow{3}{*}{$\begin{array}{l}.083 \\
1.056\end{array}$} & \multirow{3}{*}{$\begin{array}{l}.859 \\
7.034\end{array}$} \\
\hline & Familiar & 1.003 & .484 & 4.293 & 1 & .038 & 2.725 & & \\
\hline & Intersección & -9.760 & 3.073 & 10.085 & 1 & .001 & & & \\
\hline \multirow{3}{*}{ Participativo } & Mercado & 1.871 & .887 & 4.447 & 1 & .035 & 6.496 & \multirow{3}{*}{$\begin{array}{l}1.141 \\
.029 \\
1.629\end{array}$} & \multirow{3}{*}{$\begin{array}{l}36.975 \\
.877 \\
23.289\end{array}$} \\
\hline & Jerárquica & -1.835 & .869 & 4.458 & 1 & .035 & .160 & & \\
\hline & Familiar & 1.818 & .679 & 7.178 & 1 & .007 & 6.160 & & \\
\hline
\end{tabular}

*Categoría de referencia: Liderazgo autocrático.

*Reference category: Autocratic leadership.

Fuente: Elaboración propia

Source: Own elaboration

Asimismo, cuando una empresa también tienen un enfoque hacia una cultura de tipo jerárquica, es menos probable que exista un liderazgo de consulta que un liderazgo autocrático; lo anterior indica que no es de mucha importancia tomar en cuenta lo que los empleados prefieran o las opiniones y consejos que den al tomar una decisión importante (de consulta), debido a que la empresa está muy estructurada y guiada por normas, reglas y políticas (jerárquica) que se deben llevar a cabo, pues ya están estipuladas por los altos mandos y se deben respetar y llevar a cabo tal como son (autocrático).

De igual forma, en una organización es más probable que predomine un estilo de liderazgo participativo que un liderazgo autocrático cuando la empresa está enfocada hacia una cultura de tipo mercado y menos probable que exista un liderazgo participativo que un estilo de liderazgo autocrático cuando existe un enfoque hacia la cultura tipo jerárquica.

Esto porque cuando una organización tiene un enfoque hacia la cultura de tipo mercado a los empleados les interesa ser escuchados y hacerse partícipes al tomar una decisión en conjunto (participativo), en donde se aborden aspectos sobre el mercado, la competencia, etc. es decir cuando se aborden aspectos tanto externos como internos (mercado) pues en muchas ocasiones son los 
empleados quienes saben más al respecto de lo que sucede en el entorno de la organización a diferencia de los dueños o los altos mandos.

Es por ello que en las empresas donde prevalece un liderazgo participativo no se manifiesta el liderazgo autocrático donde solo se interesan por dictar órdenes esperando que se lleven a cabo, en un ambiente donde todo es estructurado y rígido bajo normas y reglas transmitidas por los altos mandos de la empresa (jerárquica), es así que es menos probable que el liderazgo participativo esté presente cuando la cultura jerárquica también lo está.

Así pues, mientras que una organización mantenga como principal enfoque su estructura, reglas, normas, políticas, entre otros aspectos, será mayor la probabilidad de que siempre exista un liderazgo autocrático que cualquier otro tipo de ellos, debido a que su principal función es dictar órdenes sin tener preocupación por quien este alrededor (ver Tabla 7).

Dentro del modelo de regresión logística multinomial se detectó que en las empresas familiares es más probable que exista cualquier otro tipo de liderazgo que un liderazgo autocrático, probablemente debido a que en un ambiente donde se encuentra la familia es más importante tomar en cuenta la opinión de los demás, preocuparse por ellos y hacerles saber también que todos son importantes dentro de la gestión de la misma, independientemente del tipo de cultura organizacional al que estén enfocados.

Tabla 7. Relación entre estilos de liderazgo y tipos de cultura organizacional.

Table 7. Relationship between the leadership styles and organizational culture types.

\begin{tabular}{|c|c|c|}
\hline $\begin{array}{c}\text { Tipo de } \\
\text { liderazgo } \\
\text { Leadership } \\
\text { styles }\end{array}$ & $\begin{array}{l}\text { Tipo de cultura } \\
\text { Culture types }\end{array}$ & $\begin{array}{c}\text { Relación } \\
\text { Relationship }\end{array}$ \\
\hline & Clan (+) & $\begin{array}{l}\text { Al existir una cultura tipo clan es más probable que exista un } \\
\text { liderazgo democrático que uno autocrático }\end{array}$ \\
\hline Democrático & Jerárquica (-) & $\begin{array}{l}\text { Al existir una cultura tipo jerárquica es menos probable que exista } \\
\text { un liderazgo democrático que uno autocrático. }\end{array}$ \\
\hline De consulta & Jerárquica (-) & $\begin{array}{l}\text { Al existir una cultura jerárquica es menos probable que exista un } \\
\text { liderazgo de consulta que un liderazgo autocrático }\end{array}$ \\
\hline & Mercado (+) & $\begin{array}{l}\text { Al existir una cultura de mercado es más probable que exista un } \\
\text { liderazgo participativo que uno autocrático }\end{array}$ \\
\hline Participativo & Jerárquica (-) & $\begin{array}{l}\text { Al existir una cultura tipo jerárquica es menos probable que exista } \\
\text { un liderazgo participativo que tuno autocrático. }\end{array}$ \\
\hline
\end{tabular}

*Categoría de referencia: Liderazgo Autocrático

Fuente: Elaboración propia.

*Reference category: Autocratic leadership

Source: Own elaboration. 


\section{Discusión o Conclusiones}

De acuerdo con Giritli, Öney-Yaz, Topçu-Oraz y Acar (2013), Schimmoeller (2010) así como en el presente estudio la cultura se analizó con cuatro tipos que son clan, adhocrática, de mercado y jerárquica, mientras para Taormina (2008) considera aceptable analizar la cultura organizacional con tres tipos de ella, los cuales son la burocrática, la innovadora y de apoyo pues creen que los comportamientos en los lideres serán más flexibles al analizarlos con estos tipos de cultura, mientras que para Santoro (2006) menciona que la cultura de una empresa no está dada solamente por diversos tipos de ella sino que se basa en distintos componentes que juntos la conforman; es por ello que Fernández y Bringmann (2007) afirman que a través de las culturas organizacionales y de los diferentes estilos de liderazgo ejercidos en una empresa ya sea familiar o no se puede alcanzar el éxito o fracaso.

Por otra parte, según Zheng, Wu, Xie y Li (2018) analizan el concepto de liderazgo enfocándose en solamente dos estilos de liderazgo que son el transformacional y transaccional pues están presentes cuando predominan cualquier tipo de cultura excepto la de tipo clan, además que para Schimmoeller (2010) también considera conveniente analizar con estos dos estilos agregando el Laissez-faire; de igual forma, Shamas-ur-Rehman y Ofori (2009) señalan que solamente con un estilo de liderazgo es suficiente para demostrar que si es necesario y tomado en cuenta dentro de las organizaciones y es el liderazgo ético; mientras que para Santoro (2006) no es necesario categorizar al liderazgo en diversos estilos sino a través de un inventario de perfiles de los líderes de cada organización.

De igual forma, según Giritli, Öney-Yaz, Topçu-Oraz y Acar (2013) los resultados encontrados apoyan la aseveración de que en empresas del sector de la construcción Turco se encuentran más inclinadas por los tipos de cultura de clan y jerárquica, además de conocer que los estilos de liderazgo más predominantes en dicho sector son el autocrático seguido del tipo democrático, pues la mayoría de las organizaciones se encuentran bajo estos dos estilos, al igual que en el sector comercial de Ciudad Obregón, Sonora donde prevalece el tipo de liderazgo autocrático seguido del democrático, por el contrario existen aspectos relacionados con la cultura organizacional que no se hacen presentes en las empresas de ninguno de los sectores comparados tales como los relacionados con el tipo de cultura adhocrática que no tiene presencia ni relación con ningún estilo de liderazgo; no obstante, para Zheng, Wu, Xie y Li (2018) quienes realizaron una investigación en China mencionan que la cultura tipo adhocrática si es relevante y tiene 
presencia dentro del sector de la construcción y esto es porque este tipo de cultura es caracterizada por ser dinámica, que busca el crecimiento y la innovación además de tomar riesgos, por lo que dentro del sector de la construcción se ha vuelto imperativo debido al crecimiento de la competencia.

Además, otro claro ejemplo a contrastar, es que según Giritli, Öney-Yaz, Topçu-Oraz y Acar (2013) cuando las empresas tienden a adoptar una cultura tipo clan es más probable que predomine un estilo de liderazgo democrático que un autocrático, así pues, se puede decir que en el sector de la construcción sobresale el tipo de liderazgo de consulta; al igual que en la presente investigación ya que cuando las empresas se enfocan en tener una cultura tipo clan es más probable que predomine el tipo de liderazgo democrático que cualquier otro estilo, mientras que cuando se hace presente el tipo de liderazgo de consulta en el sector comercial de Ciudad Obregón, Sonora es más probable que predomine la cultura tipo de mercado que jerárquica.

Aunado a lo anterior, Schimmoeller (2010) desarrolló una investigación en Estados Unidos donde afirma que los diferentes estilos de liderazgo que convergen en una organización pueden encontrarse en un tipo específico de cultura organizacional; dicho esto, se concuerda con dicha afirmación ya que en el presente estudio resultó que cuando predomina algún estilo de liderazgo también sobresale un tipo de cultura que es a la que está más enfocada la empresa.

Así pues, las variables de control analizadas en la presente investigación demostraron no tener significancia por no presentar ningún dato significativo, a diferencia de Giritli, Öney-Yaz, Topçu-Oraz y Acar (2013) que establecen que el tamaño de la empresa sí resultó ser un factor bastante importante para que puedan resaltar diversos estilos de liderazgo.

Ahora bien, como conclusiones cabe mencionar que, una vez analizado el modelo de regresión multinomial en las estimaciones de parámetros obtenidas mediante el programa SPSS versión 25, es posible establecer diversas conclusiones dadas a partir de los resultados observados en el modelo, pues con la investigación realizada se pudo constatar que las empresas familiares sobresalen por encima de las que no son consideradas familiares y eso se pudo comprobar gracias al modelo de regresión logística mutinomial realizado en el presente estudio ya que solamente las organizaciones familiares fueron las que obtuvieron datos significativos con relación a las variables de estudio a diferencia de las empresas no familiares, por ello solo se muestran los resultados de las empresas familiares ya que dentro del modelo son las que tuvieron datos significativos 
En ese sentido, cabe resaltar que dentro de los estudios analizados y los comparados anteriormente se sigue sin haber encontrado investigaciones realizadas en empresas de carácter familiar con el mismo método utilizado en la presente investigación, el de regresión logística multinomial, es por ello que no ha sido posible hacer comparaciones entre estudios contrastando los resultados obtenidos sobre las estimaciones obtenidas en el modelo visto en la Tabla 6.

Ahora bien, el estudiar y profundizar en las variables de liderazgo y cultura organizacional en un contexto tan complejo como lo son las empresas familiares, contribuye a explicar y dar un mayor aporte a la relación que guardan entre sí, además de conocer los aspectos a los que más enfocados se encuentran y saber hacia dónde quieren dirigirse, pues a partir de allí es la forma en la que llevaran a cabo las actividades de su gestión, tal como es posible observarse en la Tabla 7, ya que dependiendo de a donde se enfoquen es la manera en la que trabajarán en conjunto para lograr cada uno de sus objetivos, al mismo tiempo que eso será lo que impregne en el entorno organizacional.

Por otro lado, como se pudo observar en la Tabla 4 se considera necesario que los conflictos que se presenten dentro de las organizaciones se resuelvan por medio del liderazgo ejercido, puesto que siempre existe un estilo de liderazgo que más predomina dentro de cada organización, con el fin de que puedan seguir subsistiendo dentro del mercado y poder así mitigar la desaparición que se está provocando en este tipo de organizaciones, ya que año con año son cada vez más las empresas que dejan de existir, particularmente este tipo de empresas por el hecho de considerarse complejas a diferencia de las que no son consideradas familiares.

Aunado a ello, cabe señalar que otra aportación lograda dentro de esta investigación es el poder indagar dentro de un contexto como son las organizaciones de carácter familiar en Ciudad Obregón, Sonora, en donde anteriormente no se han podido analizar las mismas variables de estudio, además de poder compararlas con las empresas que no son consideradas familiares.

Adicionalmente, gracias a la participación obtenida de los informantes, se pudo constatar que la presente investigación también demuestra que en una organización es posible contar con varios estilos de liderazgo y no solamente uno, pues depende de la situación y el momento en el que se deben tomar las decisiones, sin embargo, a pesar de que algunas organizaciones solamente fueron caracterizadas por un solo estilo de liderazgo, es fundamental comenzar a realizar lo que otros autores exponen, tal como el comparar la cultura con otros estilos de liderazgo, ya que existen más de ellos. 
Así pues, con el presente estudio desarrollado se continúa con el camino de seguir descubriendo pautas que contribuyan ayudar a las organizaciones de carácter familiar, conociendo lo que sucede dentro de su gestión y al mismo tiempo poder tomar buenas decisiones ante cualquier situación y así seguir subsistiendo a través del tiempo.

Por consiguiente, algunas de las propuestas para las empresas familiares es que deben buscar siempre la mejora sobre la relación de las variables de estudio, fomentando al mismo tiempo el ejercicio de liderazgo dentro de las mismas, con la finalidad de preservar una buena cultura organizacional, y a la vez permitir que los integrantes de la misma cohabiten dentro de un buen ambiente de trabajo.

De igual forma, otro aspecto a tomar en consideración es que los responsables de las empresas o los dueños quienes son las cabezas principales de las organizaciones, y en algunos casos también de las familias puedan comprender tanto las actividades de la organización como la opinión que los empleados puedan tener, pues de esta manera también se podrán resolver y evitar problemáticas ya sea entre los empleados que sean o no familiares, buscando el mejor futuro para todas las partes involucradas.

Dicho de otro modo, no prestar atención o dar la debida importancia a quienes conforman la empresa puede ser la causa de tener más problemáticas dentro de la gestión, por ello es necesario que el líder debe preocuparse por tomar la mejor decisión tomando en cuenta que se obtenga un beneficio tanto para la empresa, la familia y todos los demás empleados.

Otra de las recomendaciones es seguir analizando dentro del contexto de la empresa familiar con otros estilos de liderazgo y/o con otros tipos de cultura con el fin de conocer si otro tipo de liderazgo puede tener relación con algún otro tipo de cultura, además de conocer si los resultados arrojados permiten tener más comparaciones entre las variables y covariables que sean analizadas en la investigación.

De la misma manera, es importante que al realizar un análisis estadístico como el realizado en el presente estudio es significativo tener en consideración obtener una muestra grande de organizaciones, ya sea abarcando otros sectores u otros tamaños, pues ello permitirá obtener un modelo más eficaz con más comparaciones en la variable de referencia seleccionada, así como con las variables factores y covariables.

Por último, sería interesante conocer similitudes y diferencias entre investigaciones semejantes al presente estudio, a través de los hallazgos encontrados, dentro de la gestión de las 
empresas familiares, pues por el hecho de considerarse un contexto complejo, puede que los resultados cambien ya que el liderazgo y la cultura también cambian.

\section{$\underline{\text { Referencias }}$}

Aguirre, G., Serrano, B., \& Sotomayor, G. (2017). El liderazgo de los gerentes de las pymes de Machala. Universidad y Sociedad. 9 (1), 187-195. Recuperado de http://scielo.sld.cu/pdf/rus/v9n1/rus27117.pdf

Aira, M. (2016). La sucesión exitosa en las empresas familiares. Orbis. Revista Científica Ciencias Humanas, 11(33) 82-104.

Alabart, Y., Cruz, T., \& Pila, M. (2006). Impacto del liderazgo en la cultura organizacional, desde la perspectiva de género: estudio preliminar. Folletos Gerenciales, 10(12).

Aristimuño, A., \& Parodi, J. (2017). Un Caso Real de Combate al Fracaso en la Educación Pública: Una Cuestión de Acompañamiento, Liderazgo y Cultura Organizacional. Revista Iberoamericana sobre Calidad, Eficacia y Cambio en Educación, 15(4), 141-157. DOI: https://doi.org/10.15366/reice2017.15.4.008

Arteaga, A., \& Soraya, R. (2009), Liderazgo resonante según Género, Multiciencias, 9 (3), 289295.

Azanza, G., Moriano, J., \& Molero, F. (2013). Authentic leadership and organizational culture as drivers of employees' job satisfaction. Journal of Work and Organizational Psychology 29, $45-50$

Bastar, A. (2006). El liderazgo en las pequeñas empresas mexicanas de propiedad familiar. Tesis inédita de maestría. Universidad Autónoma Metropolitana

Blake, R. \& Mouton, J. (1980), El nuevo Grid gerencial. México, Editorial Diana.

Boada, J., Vallejo, R., \& Macip, S. (2001). Cultura organizacional y formación continua: incidencia en la prevención de riesgos laborales. Revista de psicología del trabajo y de las organizaciones, $\quad$ 17(1), 91-107. Recuperado de https://journals.copmadrid.org/jwop/art/81e74d678581a3bb7a720b019f4f1a93

Burgoa, T., Herrera, E., \& Treviño, J. (2013). Estudio sobre la Administración de Empresas Familiares en México: Principales Problemas y Retos que Enfrentan. Daena: International Journal of Good Conscience, 8(2), 1-22. Recuperado de http://www.spentamexico.org/v8n2/A1.8(2)1-22.pdf 
Burkart, M., Panunzi, F., \& Shleifer, A. (2003). Family firms. The journal offinance, 58(65), 2167220. Recuperado de http://eprints.1se.ac.uk/24926/1/dp406.pdf

Cameron, K. S., \& Quinn, R. E. (1999). Diagnosing and changing organizational culture: Based on the competing values framework. Addison Wesley Massachusetts.

Chua, J., Chrisman, J. \& Sharma, P. (1999). Defining the family business by behavior. Entrepreneurship: Theory and Practice, 23(4), 19- 39. Recuperado de https://cemi.com.au/sites/all/publications/Chua\%20Chrisman\%20and\%20Sharma\%20199 9.pdf

CONCANACO (2018). Indicadores de Sonora. CONCANACO y SERVYTUR. Recuperado de https://www.concanaco.com.mx/documentos/indicadores-estados/Sonora.pdf

Coury, C., \& Peçanha, D. (2016). El liderazgo y la cultura organizacional en las empresas familiares - estudio de caso sistémica y psicodinámica. Bol. Acad. Paulista de Psicologia, 36 (91), 465-488. Recuperado de http://pepsic.bvsalud.org/pdf/bapp/v36n91/v36n91a14.pdf

Cruz, D., \& Torres, E. (2014). Caracterización de la cultura organizacional en empresas familiares. Management review, 1(3), 1-19

Espinoza, J., Contreras, F., \& Barbosa, D. (2015). Prácticas de liderazgo y su relación con la cultura en un grupo de países latinoamericanos. Divers.: Perspect. Psicol., 11(2), 303-317

Fernández, N., \& Bringmann, E. (2007). El impacto de la cultura organizacional y del liderazgo en las empresas familiares. Conocimiento, innovación y emprendedores: Camino al futuro. Red de bibliotecas Universitarias, (1), 3428-3444. Recuperado de file:///C:/Users/hp/Downloads/DialnetElImpactoDeLaCulturaOrganizacionalYDelLiderazgoEnL-2234313\%20(10).pdf

Forbes (2018). Las 25 empresas familiares más grandes del mundo. Recuperado de https://www.forbes.com.mx/las-25-empresas-familiares-mas-grandes-del-mundo/

Frontiera, J. (2010). Leadership and organizational culture transformation in professional sport. Journal of Leadership \& Organizational Studies, 17(1) 71-86. DOI: $10.1177 / 1548051809345253$

García, C. (2006). Una aproximación al concepto de cultura organizacional. Universitas $\begin{array}{llll}\text { Psychologica, } & 5(1), & \text { Recuperado }\end{array}$ https://www.redalyc.org/pdf/647/64750112.pdf 
Giritli, H., Öney-Yaz, E., Topçu-Oraz, G., \& Acar, E. (2013). The interplay between leadership and organizational culture in the Turkish. Revista Internacional de Gestión de Proyectos, $31,228-23$.

Gómez, G. M. (2015). Características y problemas de la sucesión en la empresa familiar desde el derecho sucesorio Argentino. CUM LAUDE Revista del Doctorado en Derecho, 3, 1-26. Recuperado de file://C:/Users/hp/Downloads/690-2111-1-PB.pdf

Gómez, S., \& Palacios, D., (2013). Modelación logística multinomial para clasificar los hogares de el salvador por nivel de pobreza. Tesis inédita. Universidad del Salvador. Recuperado de http://ri.ues.edu.sv/9807/1/19200966.pdf

Gómez-Rada, C. A. (2011). Liderazgo: conceptos, teorías y hallazgos relevantes. Cuadernos Hispanoamericanos de psicología, 2(2), 61-77. Recuperado de http://www.elmayorportaldegerencia.com/Libros/Liderazgo/[PD]\%20Libros\%20\%20Liderazgo.pdf

González, A., \& Fernández, E. (2000). La cultura de la organización en la gestión total de la calidad. Ensaios e Ciência: Ciências Biológicas. Agrárias e da Saúde, 4(3) 99-114

González, E., \& Olivié, C. (2018). Empresa familiar, emprendimiento e intraemprendimiento. EAE Business School. $\quad$ Recuperado de http://marketing.eae.es/prensa/SRC_Emprendimiento_EmpresaFamiliar.pdf

Hofstede, G. (1998). Attitudes, Values and Organizational Culture: Organization Studies, 19(3), 477 492. Recuperado de https://journals.sagepub.com/doi/10.1177/017084069801900305

Hosmer, D., \& Lemeshow, S. (2000). Applied logistic regression. Jhon Wiley: United States, NY. Recuperado de http://resource.heartonline.cn/20150528/1_3kOQSTg.pdf

Howard, E. (2006). Organizational Culture and Women's Leadership: A Study of Six Catholic Parishes. Sociology of Religion, 67(1) 81-98

Isaza, C. (2013). Transformación de la cultura organizacional: el caso de Rica Rondo y su integración con un grupo empresarial colombiano. Pensamiento \& Gestión, 34, 21-53.

Kouzes, J., \& Posner, B. (2002). The leadership challenge. Estados Unidos de América: HB printing. https://books.google.com.mx/books?hl=es\&lr=\&id=kHt_CeUoVZQC\&oi=fnd\&pg=PR13 $\underline{\& d q=l e a d e r s h i p}+\& o t s=R U s 7 d q y 3 e a \& s i g=f-$ $\mathrm{g} 3$ YXNELJnT7ccNVSfbLJCecss\#v=onepage $\& \mathrm{q}=$ leadership $\& \mathrm{f}=$ false 
Lapo, M., \& Jácome, M. (2015). El Liderazgo y su Evolución Histórica. Revista Empresarial, ICEFEE-UCSG, 9(4), 11-16. Recuperado de file:///C:/Users/hp/Downloads/DialnetElLiderazgoYSuEvolucionHistorica-6419728.pdf

León, A. (2001). Cultura organizacional y liderazgo: Reflexiones sobre algunos resultados de entidades bancarias. Revista de Psicología del Trabajo y de las Organizaciones, 17(2). 155172

Lescano, L. (2017). Cómo fortalecer el clima y la cultura de servicio a través del liderazgo de servicio del mando intermedio: caso de estudio en una compañía multinacional. Revista Empresa y Humanismo, XX (1), 65-96 https://doi.org/10.15581/015.XX.1.65-96

Libre Mercado (2018). Las empresas familiares generan el 58\% del PIB y crean más de 6,5 millones de empleos. Recuperado de https://www.libremercado.com/2018-06-25/lasempresas-familiares-generan-el-58-del-pib-y-crean-mas-de-65-millones-de-empleos$\underline{1276620900 /}$

Mendoza, M., \& Ortiz, C. (2006). El Liderazgo Transformacional, Dimensiones e Impacto en la Cultura Organizacional y Eficacia de las Empresas. Revista Facultad de Ciencias Económicas: Investigación y reflexión, XIV (1), 118-134

Meza, E. (2017). Sólo 73\% de las empresas familiares cuentan con un plan de sucesión. El Economista. Recuperado de https://www.eleconomista.com.mx/empresas/Solo-73-de-lasempresas-familiares-cuentan-con-un-plan-de-sucesion-20171113-0023.html

Molina, P., Botero, S., \& Montoya, A. (2017). Estudios de rendimiento en las empresas de familia. Una nueva perspectiva. Estudios Gerenciales, 33(142), 76-86. https://dx.doi.org/10.1016/j.estger.2016.10.009

Pico, G., \& López, M. (2006). Importancia de la actividad comercial de las empresas latinoamericanas en la transnacionalización e internacionalización. Revista Venezolana de Ciencias Sociales, 10(1), 69-85

Pirela, L. (2010). Liderazgo y cultura organizacional en instituciones de Educación Básica. Revista Venezolana de Gerencia, 15(51) 486-503

Quejada, R., \& Ávila, J. (2016). Empresas familiares: Conceptos, teorías y estructuras. Rev. esc. adm. neg, 81, 149-158. Recuperado de http://www.scielo.org.co/pdf/ean/n81/n81a08.pdf

Quintanilla, J., \& Moreira, C. (2016). Influencia del liderazgo en la relación entre cultura y eficiencia organizacional. Revista Publicando, 3(8), 357-374 
Quintanilla, J., \& Moreira, C. (2016). Influencia del liderazgo en la relación entre cultura y eficiencia organizacional. Revista Publicando, 3(8), 357-374

Red de cátedra de la empresa familiar (2018), ¿Por qué mueren las empresas familiares? Recuperado de http://www.catedraef.udc.es/

Rivera, L. (2016). Liderazgo y Cultura Organizacional en Latinoamérica. Tesis inédita. Universidad Del Rosario

Rodríguez-Suárez, P. M., Pico-González, B., \& Méndez-Ramírez, F. J. (2013). Capacidad innovadora en la empresa familiar como área de oportunidad hacia el desarrollo de México. Economía, Sociedad y Territorio, XIII (43) ,779-794. Recuperado de http://www.scielo.org.mx/pdf/est/v13n43/v13n43a9.pdf

Roldan, I., \& Bray, G. (2012). Cultura organizacional: aproximación sectorial en Bogotá. Rev. Fac. Cienc. Econ., XX (2), 19-4. Recuperado de file:///C:/Users/hp/Downloads/DialnetCulturaOrganizacional-4242052\%20(1).pdf

Salazar, M. (2006). El liderazgo transformacional modelo para organizaciones educativas que aprenden? UnIrevista, 1(3), 1-12.

Santoro, A. (2006). El liderazgo generacional en las empresas familiares y cómo afecta su dirección en la cultura de la organización. Tesis inédita de maestría. Universidad Católica Andrés Bello. Recuperado

de http://biblioteca2.ucab.edu.ve/anexos/biblioteca/marc/texto/AAQ6649.pdf

Schimmoeller, L. (2010), "Leadership styles in competing organizational cultures", Leadership Review, 10(2), 125-141.

Secretaria de Hacienda (2019). Producto Interno Bruto estatal. Estadísticas. Recuperado de: https://hacienda.sonora.gob.mx/finanzas-publicas/estadisticas/

Shamas-ur-Rehman, T., \& Ofori, G. (2009). Ethical Leadership: Examining the Relationships with Full Range Leadership Model, Employee Outcomes, and Organizational Culture. Journal of Business Ethics, 90(4), 533-547

Shanock, L., Baran, B., Gentry, W., Pattison, S., \& Heggestad, E. (2010), "Polynomial regression with response surface analysis: a powerful approach for examining moderation and overcoming limitations of difference scores”, Journal of Business \& Psychology, 25(4), 543-554. 
Siliceo, A., Casares, D., \& González, J. (1999). Liderazgo, valores y cultura organizacional. Hacia una organización competitiva. México: Mc Graw Hill. Recuperado de http://www.academia.edu/24224498/LIDERAZGO_VALORES_Y_CULTURA_ORGAN IZACIONAL

Soto, A., (2011). La empresa familiar en México. Situación actual de la investigación. Contaduría y Administración 58(2), abril-junio 2013: 135-171. Recuperado de http://www.scielo.org.mx/pdf/cya/v58n2/v58n2a7.pdf

Soumendu, B. (2009). Organizational Culture \&Transformational Leadership as Predictors of Employee Performance. Indian Journal of Industrial Relations, 44(4), 611-627

Stone-Johnson, C. (2014). Responsible leadership. Educational Administration Quartely, 50(4), 645-674

Tagiuri, R., \& Davis, J. (1996). Bivalent attributes of the family firm. Family Business Review, 9(2), 199-208

Taormina, R. (2008), “Interrelating leadership behaviors, organizational socialization, and organizational culture”, Leadership \& Organization Development Journal, 29(1), 85-102.

Toca, E., \& Carrilo, J. (2009). Asuntos teóricos y metodológicos de la cultura organizacional. Civilizar 9(17), 117-136

Torres, M., Paz, K., \& Salazar, F. (2002). Métodos de recolección de datos para una investigación. Universidad de Guadalajara. Facultad de Ingeniería. Recuperado de http://fgsalazar.net/LANDIVAR/ING-PRIMERO/boletin03/URL_03_BAS01.pdf

Tsui, A., Zhang, Z., Wang, H., Xin, K., \& Wu, J. (2006), "Unpacking the relationship between CEO leadership behavior and organizational culture", The Leadership Quarterly, 17(2), $113-137$

Valencia, E., \& Bonifaz, A. (2018). Modelo de Regresión Logística Multinomial para medir las preferencias que tienen los clientes en el sector farmacéutico: caso Ambato, Ecuador. Journal of Pharmacy \& Pharmacognosy Research, 6(4), 318-325. Recuperado de http://jppres.com/jppres/pdf/vol6/jppres18.365_6.4.318.pdf

Vázquez, A. (2013). Interdependencia entre el liderazgo transformacional, cultura organizacional y cambio educativo: una reflexión. Revista Iberoamericana sobre Calidad, Eficacia y Cambio en Educación, 11(1), 73-91 
Wilderon, C., Van den Berg, P., Wiersma, U. (2012). A longitudinal study of the effects of charismatic leadership and organizational culture on objective and perceived corporate performance. The Leadership Quarterly, 23, 835-848

Witzel, M. (2012). The leadership philosophy of Han Fei, Asia Pacific. Business Review, 18(4), 489-503, DOI: 10.1080/13602381.2012.690941

Zheng, j., Wu, G., Xie, H., Li, H. (2018). Leadership, organizational culture, and innovative behavior in construction projects. The perspective of behavior-value congruence. International Journal of Managing, 1753-8378. DOI 10.1108/IJMPB-04-2018-0068 


\section{$\underline{\text { Apéndice. Instrumento }}$}

El presente cuestionario tiene como finalidad analizar cuál es la relación entre la cultura organizacional y el estilo de liderazgo del responsable de la misma, en las empresas familiares de Ciudad Obregón, Sonora. Por ello, solicitamos su apoyo respondiendo de forma honesta, en entendido que la información será tratada de forma confidencial y solo con fines académicos.

Nombre de la empresa:

Años de operación: 1-5 6-10 $11-$

15__16-20_ 21 o más__ No. Empleados: 1-10 $11-30$ 31-100 101 o más

¿Cuántos familiares del dueño hay en la empresa? 0 1

Puesto: Sexo: $M$ $\mathrm{F}$ 2 3 4 o más

Edad: Menos de 20 21-30 $31-40$

Estado civil: Casado Soltero

Escolaridad: Primaria Secundaria 41-50 51 o más

Antigüedad en la empresa (años): 1-5 Preparatoria Licenciatura Otro 6-10_ 11-15 $16-20$ 21 o más

\begin{tabular}{|l|l|l|l|l|l|}
\hline $\begin{array}{l}\text { Instrucciones: Por favor lea cada } \\
\text { una de las descripciones y marque } \\
\text { con una X la respuesta que } \\
\text { considere adecuado. }\end{array}$ & $\begin{array}{c}\text { Totalmente } \\
\text { en } \\
\text { desacuerdo }\end{array}$ & $\begin{array}{c}\text { En } \\
\text { desacuerdo }\end{array}$ & $\begin{array}{c}\text { Ni de } \\
\text { acuerdo ni } \\
\text { en } \\
\text { desacuerdo }\end{array}$ & $\begin{array}{c}\text { De } \\
\text { acuerdo }\end{array}$ & $\begin{array}{c}\text { Totalmente } \\
\text { de acuerdo }\end{array}$ \\
\hline $\begin{array}{l}\text { 1.- La empresa es un lugar muy } \\
\text { personal. Es como una gran } \\
\text { familia. Los empleados comparten } \\
\text { mucho entre todos }\end{array}$ & $\begin{array}{l}\text { 2.- El liderazgo en la empresa es } \\
\text { generalmente considerado como } \\
\text { ejemplo. Se encarga de guiar, } \\
\text { facilitar o fomentar }\end{array}$ & & & & \\
\hline $\begin{array}{l}\text { 3.- El estilo de gestión de la } \\
\text { empresa se caracteriza por el } \\
\text { trabajo en equipo, el } \\
\text { consentimiento y la participación }\end{array}$ & & & & & \\
\hline $\begin{array}{l}\text { 4.- La cohesión que mantiene } \\
\text { unida a la empresa es la lealtad y la } \\
\text { confianza mutua. El compromiso } \\
\text { con esta empresa es alto }\end{array}$ & & & & & \\
\hline $\begin{array}{l}\text { 5.- La empresa hace hincapié en el } \\
\text { desarrollo humano, alta confianza, } \\
\text { la apertura y la participación } \\
\text { persisten }\end{array}$ & & & & & \\
\hline $\begin{array}{l}\text { 6.- La organización define el éxito } \\
\text { sobre la base del desarrollo de los } \\
\text { recursos humanos, trabajo en } \\
\text { equipo, el compromiso de los } \\
\text { empleados y la preocupación por la } \\
\text { gente }\end{array}$ & & & & & \\
\hline
\end{tabular}




\begin{tabular}{|c|c|c|c|c|c|}
\hline $\begin{array}{l}\text { 7.- La empresa es un lugar muy } \\
\text { dinámico y emprendedor. La gente } \\
\text { está dispuesta a poner de su parte y } \\
\text { tomar riesgos }\end{array}$ & & & & & \\
\hline $\begin{array}{l}\text { 8.- El liderazgo en la empresa se } \\
\text { considera que generalmente } \\
\text { ejemplifica el espíritu empresarial, } \\
\text { la innovación o asunción de } \\
\text { riesgos }\end{array}$ & & & & & \\
\hline $\begin{array}{l}\text { 9.- El estilo de gestión de la } \\
\text { empresa se caracteriza por la toma } \\
\text { de riesgo individual, la innovación } \\
\text { y libertad }\end{array}$ & & & & & \\
\hline $\begin{array}{l}\text { 10.- La cohesión que mantiene } \\
\text { unida a la empresa es el } \\
\text { compromiso con la innovación y el } \\
\text { desarrollo. Hay un énfasis de estar } \\
\text { a la vanguardia }\end{array}$ & & & & & \\
\hline $\begin{array}{l}\text { 11.- La empresa hace hincapié en } \\
\text { la adquisición de nuevos recursos y } \\
\text { la creación de nuevos desafíos. } \\
\text { Probar cosas nuevas y la } \\
\text { prospección de oportunidades, son } \\
\text { valoradas. }\end{array}$ & & & & & \\
\hline $\begin{array}{l}\text { 12.- La organización define el } \\
\text { éxito sobre la base de tener los } \\
\text { productos más singulares o más } \\
\text { recientes. Es un producto líder e } \\
\text { innovador }\end{array}$ & & & & & \\
\hline $\begin{array}{l}\text { 13.- La empresa está orientada a } \\
\text { los resultados. Todos se preocupan } \\
\text { mucho por realizar el trabajo. Los } \\
\text { empleados son competitivos y } \\
\text { están orientados al logro de } \\
\text { objetivos }\end{array}$ & & & & & \\
\hline $\begin{array}{l}\text { 14.- El liderazgo en la empresa es } \\
\text { generalmente considerado como } \\
\text { ejemplo y orientación a los } \\
\text { resultados }\end{array}$ & & & & & \\
\hline $\begin{array}{l}\text { Instrucciones: Por favor lea cada } \\
\text { una de las descripciones y marque } \\
\text { con una X la respuesta que } \\
\text { considere adecuado. }\end{array}$ & $\begin{array}{c}\text { Totalmente } \\
\text { en } \\
\text { desacuerdo }\end{array}$ & $\begin{array}{c}\text { En } \\
\text { desacuerdo }\end{array}$ & $\begin{array}{c}\text { Ni de } \\
\text { acuerdo ni } \\
\text { en } \\
\text { desacuerdo }\end{array}$ & $\begin{array}{c}\text { De } \\
\text { acuerdo }\end{array}$ & $\begin{array}{l}\text { Totalmente } \\
\text { de acuerdo }\end{array}$ \\
\hline $\begin{array}{l}\text { 15.- El estilo de gestión de la } \\
\text { empresa se caracteriza por una } \\
\text { competencia de difícil manejo, alta } \\
\text { demanda y logros propuestos }\end{array}$ & & & & & \\
\hline $\begin{array}{l}\text { 16.- La cohesión que mantiene } \\
\text { unida a la empresa es el énfasis en } \\
\text { el éxito y el logro de las metas }\end{array}$ & & & & & \\
\hline
\end{tabular}




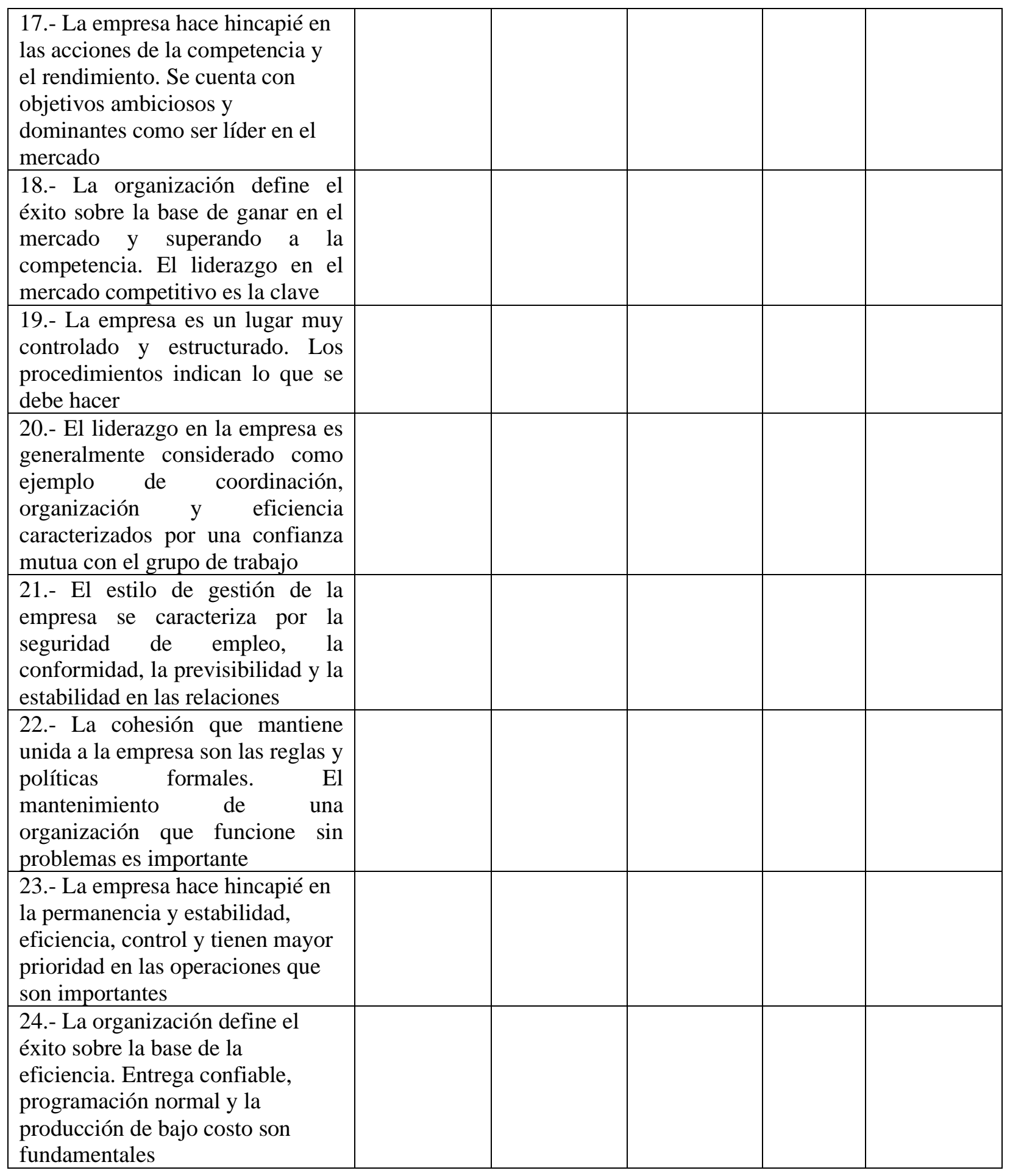




\begin{tabular}{|c|c|c|c|c|}
\hline \multicolumn{5}{|c|}{ Responsable de la empresa } \\
\hline $\begin{array}{l}\text { 25.- Marque } \\
\text { con una "X" } \\
\text { el jefe con el } \\
\text { que le } \\
\text { gustaría } \\
\text { trabajar. }\end{array}$ & $\begin{array}{lr}\text { Por lo general, } \\
\text { toma } & \text { sus } \\
\text { decisiones } & \\
\text { rápidamente y las } \\
\text { comunica a sus } \\
\text { subordinados de } \\
\text { manera clara y } \\
\text { firme. Espera que } \\
\text { lleven a cabo las } \\
\text { decisiones con } \\
\text { lealtad y sin } \\
\text { mayores } \\
\text { dificultades. }\end{array}$ & $\begin{array}{l}\text { Por lo general, toma } \\
\text { sus decisiones con } \\
\text { prontitud, pero, } \\
\text { antes de seguir } \\
\text { adelante, trata de } \\
\text { explicárselas por } \\
\text { completo a sus } \\
\text { subordinados. } \\
\text { Explica las razones } \\
\text { de las decisiones y } \\
\text { responde cualquier } \\
\text { pregunta que } \\
\text { tengan. }\end{array}$ & $\begin{array}{l}\text { Generalmente } \\
\text { consulta con sus } \\
\text { subordinados antes de } \\
\text { tomar sus decisiones. } \\
\text { Escucha sus consejos, } \\
\text { los considera y luego } \\
\text { anuncia su decisión. } \\
\text { Luego espera que } \\
\text { todos trabajen } \\
\text { lealmente para } \\
\text { implementarlo, sea o } \\
\text { no de acuerdo con el } \\
\text { consejo que dieron }\end{array}$ & $\begin{array}{l}\text { Por lo general, } \\
\text { convoca a reunión } \\
\text { con sus } \\
\text { subordinados } \\
\text { cuando hay que } \\
\text { tomar una decisión } \\
\text { importante. Pone } \\
\text { el problema ante el } \\
\text { grupo e invita a la } \\
\text { discusión. Acepta } \\
\text { el punto de vista } \\
\text { mayoritario como } \\
\text { la decisión }\end{array}$ \\
\hline $\begin{array}{l}\text { 26.- Marque } \\
\text { con una "X" } \\
\text { el Jefe con el } \\
\text { que usted } \\
\text { trabaja } \\
\text { actualmente }\end{array}$ & $\begin{array}{l}\text { Por lo general, } \\
\text { toma } \\
\text { decisiones } \\
\text { rápidamente y las } \\
\text { comunica a sus } \\
\text { subordinados de } \\
\text { manera clara y } \\
\text { firme. Espera que } \\
\text { lleven a cabo las } \\
\text { decisiones con } \\
\text { lealtad y sin } \\
\text { mayores } \\
\text { dificultades. }\end{array}$ & $\begin{array}{l}\text { Por lo general, toma } \\
\text { sus decisiones con } \\
\text { prontitud, pero, } \\
\text { antes de seguir } \\
\text { adelante, trata de } \\
\text { explicárselas por } \\
\text { completo a sus } \\
\text { subordinados. } \\
\text { Explica las razones } \\
\text { de las decisiones y } \\
\text { responde cualquier } \\
\text { pregunta que } \\
\text { tengan. }\end{array}$ & $\begin{array}{l}\text { Generalmente } \\
\text { consulta con sus } \\
\text { subordinados antes de } \\
\text { tomar sus decisiones. } \\
\text { Escucha sus consejos, } \\
\text { los considera y luego } \\
\text { anuncia su decisión. } \\
\text { Luego espera que } \\
\text { todos trabajen } \\
\text { lealmente para } \\
\text { implementarlo, sea o } \\
\text { no de acuerdo con el } \\
\text { consejo que dieron }\end{array}$ & $\begin{array}{l}\text { Por lo general, } \\
\text { convoca a reunión } \\
\text { con sus } \\
\text { subordinados } \\
\text { cuando hay que } \\
\text { tomar una decisión } \\
\text { importante. Pone } \\
\text { el problema ante el } \\
\text { grupo e invita a la } \\
\text { discusión. Acepta } \\
\text { el punto de vista } \\
\text { mayoritario como } \\
\text { la decisión }\end{array}$ \\
\hline
\end{tabular}

¡Muchas gracias por su apoyo! 